\title{
Regression Method
}

National Cancer Institute

\section{Source}

National Cancer Institute. Regression Method. NCI Thesaurus. Code C53237.

Regression analysis provides a "best-fit" mathematical equation for the relationship between the dependent variable (response) and independent variable(s) (covariates). There are two major classes of regression - parametric and non-parametric. Parametric regression requires choice of the regression equation with one or a greater number of unknown parameters. Linear regression, in which a linear relationship between the dependent variable and independent variables is posited, is an example. The aim of parametric regression is to find the values of these parameters which provide the best fit to the data. The number of parameters is usually much smaller than the number of data points. In contrast, the non-parametric regression requires no such a choice of the regression equation. 